\title{
PENGEFEKTIFAN LAHAN PARKIR DI FAKULTAS MIPA UNIVERSITAS SEBELAS MARET SURAKARTA
}

\author{
Ahmad Khusnur Almursyidi, Asnan Anwari, Wahyu Setyawan \\ Jurusan Fisika,Universitas Sebelas Maret,Surakarta,Jl. Ir. Sutami No.36 \\ A,57126 \\ email: Ahmadkhusnur01@Student.uns.ac.id
}

\begin{abstract}
ABSTRAK
Fakultas MIPA Sebagai salah satu fakultas di Universitas Sebelas Maret yang memiliki jumlah mahasiswa,dosen,karyawan dan lain-lain yang cukup besar,keadaan ini yang menyebabkan permintaan parkir di Fakultas MIPA merupakan permasalahan yang tidak dapat diabaikann karena Fakultas MIPA sebagai pusat kegiatan civitas akademika membutuhkan penataan kampus yang baik serta populasi masyarakat kampus terus meningkat setiap tahun akademik.Penelitian ini bertujuan untuk mengetahui kebutuhan parkir di Fakultas MIPA ,mengetahui jumlah volume kendaraan baik sepeda motor dan mobil di Fakultas MIPA,menganalisa solusi penanganan parkir di Fakultas MIPA.Dalam mengatasi persoalan diatas pengelolaan parkir dan manajemen parkir dibutuhkan untuk membantu pengguna parkir di Fakultas MIPA.Pengelolaan seperti pembuatan pola parkir bersudut,restorasi lahan dan penambahan petugas atau manajemen parkir diharapkan dapat memberikan solusi yang bermanfaat bagi pengguna parkir di Fakultas MIPA.
\end{abstract}

Kata kunci : Fakultas Mipa, Parkir, Vertical Building

\section{PENDAHULUAN}

\subsection{Latar Belakang}

Fakultas MIPA sebagai salah satu fakultas di Universitas Sebelas Maret Surakarta yang memiliki jumlah mahasiswa,dosen,karyawan ,dan lain-lain yang cukup besar,keadaan ini menyebabkan permintaan parkir di Fakultas MIPA merupakan permasalahan yang tidak dapat diabaikan karena Fakultas MIPA sebagai pusat kegiatan civitas akademika membutuhkan penataan kampus yang baik serta populasi masyarakat kampus yang terus meningkat setiap tahun akademik.

Untuk itu seiring dengan bertambahnya jumlah mahasiswa,dosen,karyawan ,dan lain-lain yang menuju Fakulas MIPA maka menimbulkan masalah kebutuhan ruang parkir dimana pada saat jam-jam tertentu terkadang area parkir tidak dapat menampung jumlah kendaraan yang akan parkir,maka akan dicari pemecahan dari kebutuhan lokasi parkir ini sehingga diperoleh sistem 
pengelolaan dan manajemen parkir yang baik sehingga dapat memenuhi kebutuhan akan pemanfaatan parkir.

Untuk itu penelitian ini perlu dilakukan agar angka kebutuhan parkir serta bagaimana pengelolaan dan manajemen parkir dapat diketahui secara pasti.Perencanaan pengelolaan parkir dengan pembuatan pola parkir bersudut,restorasi lahan,dan perbaikan manajemen parkir berupa penambahan petugas parkir diharapkan mampu memberikan solusi agar lahan di Fakultas MIPA lebih efektif.

\subsection{Rumusan Masalah}

Berdasarkan perumusan masalah diatas maka rumusan masalah penulisan artikel ini:

1. Berapa volume kendaraan yang parkir di Fakultas MIPA

2. Bagaimana kinerja parkir (penambahan petugas parkir,restorasi lahan parkir dan pembangunan vertical building)

\subsection{Tujuan}

Berdasarkan perumusan masalah diatas maka tujuan penulisan artikel ini :

1. Mengetahui berapa volume kendaraan yang parkir di Fakultas MIPA

2. Menganalisa kinerja parkir (penambahan petugas parkir,restorasi lahan parkir dan pembangunan verical building)

\subsection{Manfaat}

Manfaat dari evaluasi kinerja parkir ini,diharapakan dapat memberikan solusi dalam mengatasi jumlah kendaraan parkir yang semakin meningkat dengan situasi kondisi lokasi parkir yang ada saat ini.

\subsection{Lokasi Penelitian}

Gambar dibawah ini adalah lokasi Fakultas MIPA Universitas Sebelas Maret Surakarta tempat dilakukan penelitian beralamat di Jl. Ir. Sutami No.36 A Surakarta-Jawa Tengah.

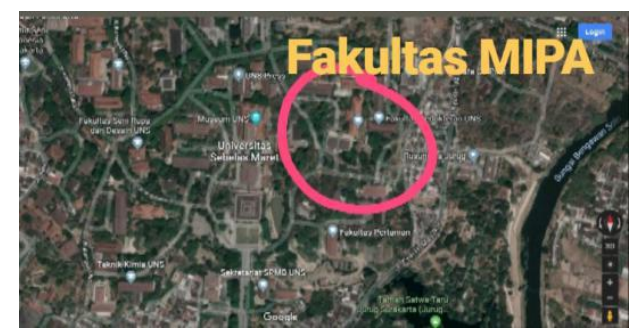

Gambar 1.1 Lokasi Fakultas MIPA

Sumber : https://maps.google.co.id/

\section{LANDASAN TEORI}

2.1. Umum

Parkir adalah keadaan tidak bergerak dari suatu kendaraan yang bersifat sementara (Direktorat Jendral Perhubungan Darat, 1996, 1). 
Selain Pengertian di atas beberapa ahli memberikan definisinya tentang parkir, yaitu :

1. Semua kendaraan tidak mungkin bergerak terus, pada suatu saat ia harus berhenti untuk sementara waktu (menurunkan muatan) atau berhenti cukup lama yang disebut parkir.

2. Parkir adalah keadaan tidak bergerak suatu kendaraan yang tidak bersifat sementara (Keputusan Direktur Jenderal Perhubungan Darat Nomor :

272/Hk.105/DRJD/96).

Berdasarkan dari definisi-definisi di atas maka dapat ditarik kesimpulan bahwa parkir adalah suatu keadaan tidak bergerak suatu kendaraan bermotor atau tidak bermotor yang dapat merupakan awal dari perjalanan dengan jangka waktu tertentu sesuai dengan keadaan dan kebutuhannya yang membutuhkan suatu areal sebagai tempat pemberhentian yang diselenggarakan baik oleh pemerintah maupun pihak lain yang dapat berupa perorangan maupun badan usaha. Dasar pengaturan mengenai parkir adalah Keputusan Menteri Perhubungan Nomor: KM 66 Tahun 1993 tentang Fasilitas Parkir untuk Umum dan Keputusan Menteri Perhubungan Nomor: KM 4 Tahun 1994 tentang Tata Cara Parkir Kendaraan Bermotor di Jalan telah diatur fasilitas parkir untuk umum dan tata cara parkir di jalan, dengan Keputusan Dirjen Perhubungan Darat No. 272/HK.105/DRJD/96.

Sarekomendasi utama dari kebijakan parkir sebagai bagian dari kebijakan transportasi adalah sebagai berikut:

a. Untuk mengendalikan jumlah kendaraan yang masuk kesuatu kawasan,

b. Meningkatkan pendapatan asli daerah yang dikumpulkan melalui retribusi parkir,

c. Meningkatkan fungsi jalan sehingga sesuai dengan peranannya,

d. Meningkatkan kelancaran dan keselamatan lalu lintas

e. Mendukung tindakan pembatasan lalu lintas lainnya.

Penetapan lokasi fasilitas parkir untuk umum dilakukan oleh Menteri.

Penetapan lokasi dan pembangunan fasilitas parkir untuk umum, dilakukan dengan memperhatikan:

a. Rencana umum tata ruang daerah;

b. Keselamatan dan kelancaran lalu lintas;

c. Kelestarian lingkungan;

d. Kemudahan bagi pengguna jasa.

\subsection{Karakteristik Parkir}

Karakteristik parkir dimaksudkan sebagai sifat-sifat dasar yang memberikan penilaian terhadap pelayanan parkir dan permasalahan parkir yang terjadi pada lokasi studi. Berdasarkan karakteristik parkir, akan dapat diketahui kondisi perparkiran yang terjadi pada lokasi studi seperti mencakup volume parkir, lama waktu parkir, kapasitas parkir.

\subsection{Type Parkir}

\subsubsection{Parkir menurut tempat}




\section{a. Off Street Parking}

Off street parking adalah lahan parkir yang letaknya diluar badan jalan. Parkir jenis ini membutuhkan biaya yang sangat besar atau mahal. Oleh karena itu fasilitas parkir diluar jalan dapat diselenggarakan oleh pemerintah melalui badan usaha milik pemerintah, atau badan hukum Indonesia, atau warga negara Indonesia.

Parkir diluar jalan ini terdiri dari :

\section{Pelataran Parkir}

Pelataran parkir mobil adalah fasilitas parkir diluar yang paling sederhana.

Pelataran parkir ini biasanya dibagi-bagi menggunakan kerb yang

permukaannya dilapisi dengan perkerasan beton, serta diberi marka untuk menuju tempat parkir dan jalan untuk mobil.

2. Gedung Parkir Bertingkat

Gedung parkir bertingkat ini banyak digunakan di perkotaan, karena penduduk kota memiliki kegiatan yang relatif sibuk. Pemanfaatan parkir bertingkat ini selain dapat dirancang untuk kapasitas yang besar juga untuk menyiasati mahalnya harga tanah.

3. Garasi Parkir Bawah Tanah

Padatnya perkotaan dan sempitnya kota, maka garasi parkir bawah tanah layak untuk dilakukan di perkotaan. Biasanya parkir bawah tanah ini dibuat di bawah pertokoan atau plaza. Selain dapat menampung dalam jumlah besar, parkir bawah tanah juga terkesan rapi. Melihat kembali mengenai sejarah pembuatan garasi bawah tanah pertama kali dibuat di San Fransisco dan mampu menampung 1500 kendaraan.

\subsubsection{Posisi Parkir}

Bila ditinjau dari posisi, parkir dapat dibedakan menjadi tiga, yaitu:

a. Parkir Tegak Lurus

Parkir tegak lurus atau parkir bersudut 90o banyak digunakan untuk lalu lintas dua arah dan merupakan lay out yang paling efisien apabila ukuran halaman parkir dan bentuk parkir yang sesuai. Pola parkir ini mempunyai daya tampung lebih banyak. 


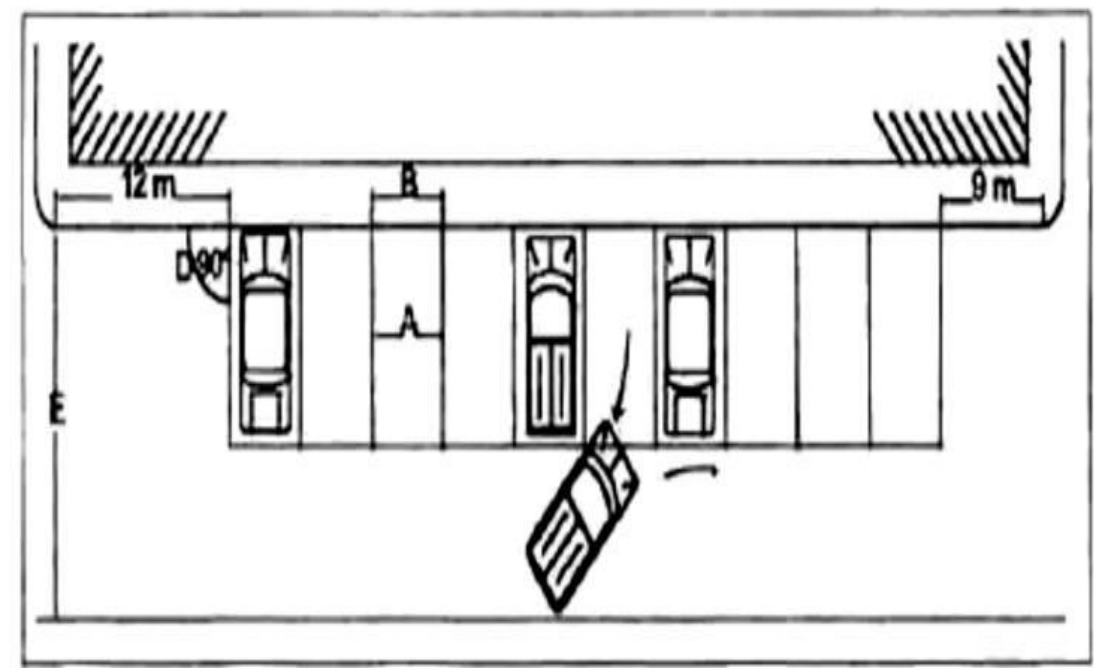

Gambar 2.1. Parkir Tegak Lurus

Sumber: Keputusan Menteri Perhubungan No. 4 (1994)

\section{b. Parkir Pararel}

Untuk jalan yang tidak terlalu lebar atau sempit, penggunaan parkir pararel akan sangat menguntungkan karena tidak mengurangi kapasitas jalan. Tetapi daya tampungnya tidak terlalu banyak, dan parkir semacam ini jarang digunakan selain tidak mampu menampung dalam jumlah besar serta menyulitkan pengemudi yang hendak parkir.

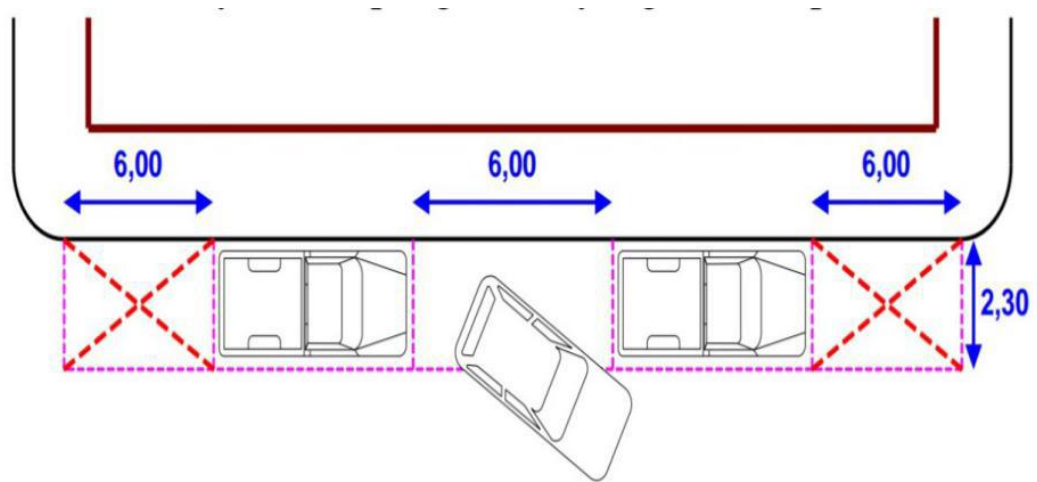

Gambar 2.2. Pola Parkir Pararel

Sumber: Keputusan Menteri Perhubungan No. 4 (1994)

c. Parkir Bersudut

Pola parkir ini mempunyai daya tampung lebih banyak jika dibandingkan dengan pola parkir pararel, dan kemudahan serta kenyamanan pengemudi untuk melakukan manuver masuk dan keluar ruangan parkir lebih besar jika dibandingkan dengan pola parkir dengan tegak lurus (Suprianto dan Mudjanarko,2015) 


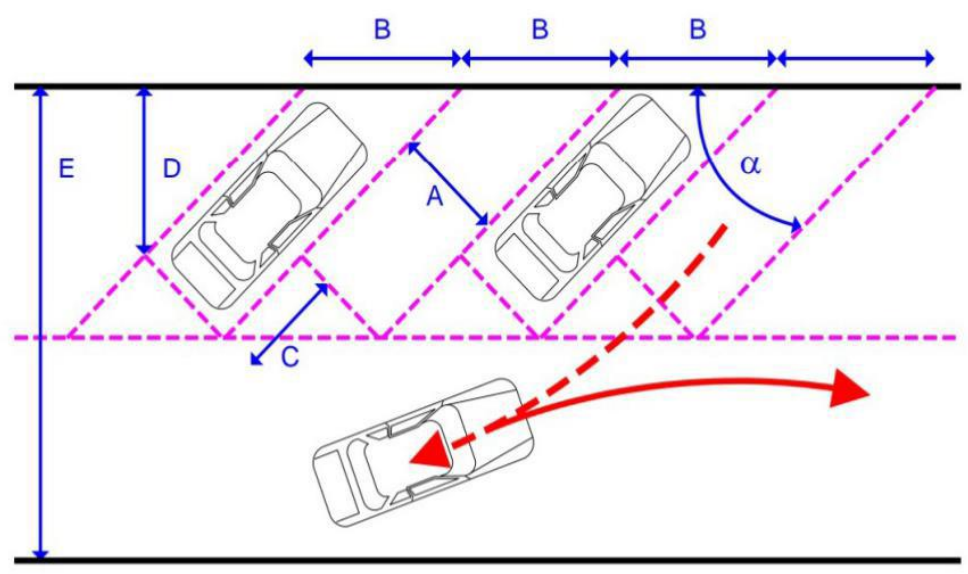

Gambar 2.3 Pola Parkir Menyudut

Sumber: Keputusan Menteri Perhubungan No. 4 (1994)

\section{METODOLOGI}

\subsection{Objek Penelitian}

Universitas Sebelas Maret berdiri sejak 11 Maret 1976, yang awalnya merupakan gabungan dari 5 perguruan tinggi yang ada di Surakarta. 5 perguruan tinggi tersebut: Institut Pelatihan dan Pendidikan Guru Surakarta, Sekolah Menengah Olahraga Surakarta, Akademi Administrasi Bisnis Surakarta, Universitas Gabungan Surakarta (Universitas ini adalah gabungan dari beberapa universitas di Surakarta termasuk Universitas Islam Indonesia Surakarta) dan Fakultas Obat-obatan Departemen Pertahanan dan Keamanan Pengembangan Pendidikan Tinggi Nasional Surakarta. Pengabungan beberapa perguruan tinggi tersebut, mempunyai satu tujuan yang besar, yakni meningkatkan kualitas pendidikan tinggi di Surakarta. Universitas Sebelas Maret berada di Jl. Ir. Sutami No.36 A, Pucangsawit, Kec. Jebres, Kota Surakarta, Jawa Tengah.

\subsection{Jenis Data}

Jenis data yang dipakai pada artikel ini yaitu data Primer atau data yang diperoleh secara langsung, meliputi :

\section{a. Metode Observasi}

Pengumpulan data melalui pengamatan dan pencatatan terhadap gejala atau peristiwa yang diselidiki pada objek penelitian secara langsung, misalnya mengamati proses pengelolaan data dengan cara lama, kemudian mengidentifikasi berbagai masalah yang timbul, dan mencari solusinya. 


\section{b. Survey Online}

Pengumpulan data dengan sebuah aplikasi Survey yang mana dibuat dalam bentuk pesan siaran atau jarkoman. Kemudian pesan siaran tersebut di share di media sosial dengan harapan banyak partisipan yang bakal mengisi form survey yang telah dibuat. Ketika sudah banyak data masuk, barulah data tersebut diolah.

\section{c. Interview/Wawancara}

Pengumpulan data melalui tatap muka dan tanya jawab langsung dengan sumber data atau pihak-pihak yang berkepentingan yang berhubungan dengan penelitian, misalnya tanya jawab kepada pihak instansi tentang parkir meliputi luas lahan, permasalahan parkir dan jumlah kendaraan yang parkir tiap harinya.

\section{PEMBAHASAN}

\subsection{Analisa Permasalahan}

Jumlah mahasiswa yang begitu besar dan banyaknya jumlah pengguna sepeda motor merupakan permasalahan tersendiri bagi Mahasiswa Fakultas MIPA Universitas Sebelas Maret. Hal tersebut mengakibatkan membeludaknya sepeda motor yang parkir di Fakultas MIPA yang mana diketahui lahan parkiran MIPA yang tidak terlalu besar. Sehingga jumlah sepeda motor yang di parkirkan tidak sebanding dengan lahan yang tersedia. Selain itu sistem parkir kendaraan bermotor di Fakultas MIPA masih menggunakan sistem manual sehingga cukup rentan keamanannya.

Untuk memberikan solusi dari permasalahan diatas harus diterapkan perancangan sistem parkir yang dapat mengoptimalkan lahan yang tidak terlalu luas tersebut. Salah satunya yaitu dengan menggunakan perancangan desain parkir yang sesuai pedoman. Perancangan desain parkir yang digunakan adalah rancangan sesuai dengan Pedoman Teknis Penyelenggaraan Fasilitas Parkir tahun 1966 yaitu menggunakan desian tata pola parkir bersudut dengan sudut (a) $30^{\circ}$, (b) $45^{\circ}$, (c) $60^{\circ}$, (d) $90^{\circ}$. Desain pola parkir bersudut digunakan untuk mengoptimalkan daya tampung kendaraan sehingga dapat menampung lebih banyak kendaraan. Permasalahan yang dialami mahasiswa FMIPA UNS berkaitan dengan tata parkir adalah : 1) penataan parkir yang kurang tertib, 2) Pengguna parkir tidak mau mengisi parkiran yang jauh, 3) Banyak sparepart motor yang rusak akibat kurang tertib, 4) Lokasi parkir yang berlubang dan rusak sehingga tak bisa diisi, 5) Sirkulasi parkir yang tidak lancar. Harapan 
pengguna berdasarkan hasil wawancara adalah sistem desain pola parkir yang baik, pembenahan pada bagian lokasi parkir yang rusak, dan ketertiban dalam penempatan kendaraan sesuai satuan ruang parkir yang ada.

\begin{tabular}{|r|r|}
\hline Sudut & $\begin{array}{l}\text { Jumlah } \\
\text { Kendaraan }\end{array}$ \\
\hline $30^{\circ}$ & 84 \\
\hline $45^{\circ}$ & 118 \\
\hline $60^{\circ}$ & 148 \\
\hline $90^{\circ}$ & $\mathbf{1 7 6}$ \\
\hline
\end{tabular}

Tabel 1. Daya Tampung Parkir Bersudut

Tabel 1 menunjukkan alternatif sudut beserta daya tampung maksimalnya. Desain pola parkir bersudut yang optimal didapatkan dengan sudut $90^{\circ}$ dengan daya tampung sebesar 176 kendaraan. Desain pola parkir bersudut $90^{\circ}$ dapat menjawab permasalahan yang dialami warga FMIPA UNS terkait dengan luas lahan parkir yang harus sesuai dengan volume kendaraan yang ada. Keuntungan dari desain pola parkir bersudut $90^{\circ}$ antara lain: 1) Posisi parkir sepeda motor tidak mengganggu ruas jalan sirkulasi masuk sepeda motor, lebar ruas masih memenuhi standar minimal jalur sirkulasi sebesar 1.5 meter, dan jumlah kendaraan yang dapat ditampung optimal. Hal ini membantu mengatasi permasalahan jalur sirkulasi parkir sepeda motor yang sempit. Pemetaan satuan ruang parkir dengan sudut $90^{\circ}$, membantu mengatasi permasalahan penataan parkir yang kurang tertib, pengaturan beberapa sepeda motor yang tidak teratur. Lebar satuan ruang parkir 0,75 meter mengurangi kekhawatiran pengguna atas kerusakan sparepart yang mungkin dialami.

\section{KESIMPULAN}

Dari hasil pembahasan maka dapat disimpulkan:

5.1 Total kendaraan yang parkir di Fakultas MIPA sebanyak 176 kendaraan.

5.2 Desain pola parkir bersudut $90^{\circ}$ merupakan desain pola parkir yang paling optimal.Perlu dilakukanya restorasi lahan parkir Fakultas MIPA UNS agar kendaraan yang ditampung ditampung sebanyakn optimal. Diperlukan penambahan petugas parkir agar kendaraan dapat parkir dengan tertib dan kerusakan sparepart motor dapat diminimalisir. 


\section{DAFTAR PUSTAKA}

Direktur Jendral Perhubungan Darat. 1996. Keputusan Direktur Jenderal Perhubungan Darat tentang Pedoman Teknis Penyelenggaraan Fasilitas Parkir. Jakarta: Departemen Perhubungan.

Suhardi, B., Laksono, P.W., dan Nugraha, A.A. 2017. Desain pola parkir sepeda motor dengan pendekatan ergonomi partisipatori. Performa, 16 (1):36-43.

Suprianto, P .,dan Mudjanarko, S.W.2015.Evaluasi Kinerja Parkir di RSU Haji Surabaya.e-Jurnal Spirit Pro Patria,1(II):1-10. 